\title{
Comentarios a treinta años de Medellín
}

\section{Treinta años después de Medellín}

\author{
José I. González Faus, \\ Facultad de Catalunya, \\ Barcelona.
}

Me dan muy poco tiempo para redactar esta respuesta. Pero creo que se puede ser muy breve al hablar del significado de Medellin, siempre que se comprenda que la brevedad no es sinónimo de poca importancia, sino que la menor extensión puede ser debida a la mayor intensidad. En una palabra, Medellín será un punto de referencia constante, aún más que por sus contenidos, por su actitud.

Los contenidos están siempre llamados a cambiar, conforme cambian las circunstancias a las que van dirigidos. Por poner un ejemplo: es legítimo preguntarse si hoy (visto el cambio que se ha producido en la hisloria sobre la viabilidad de las guerras revolucionarias), Medellín diría tan expresamente como en 1968 que la "tiranía evidente y prolongada" capaz de justificar incluso una revolución amada, "puede provenir tanto de una persona como de unas estructuras evidentemente injustas" ( $P a z$ 19). Pero esto da lo mismo, siempre que no se entienda esta afirmación mía como si dijera que las estructuras han dejado de ser "evidentemente injustas". Lo siguen siendo y quizás más que entonces. Lo que no es tan evidente - vista la logística mundial- es que una revolución amada pueda cambiarlas.

¿Qué es entonces lo que convierte a Medellín en un punto de referencia constante. Ya lo he dicho: su actitud. Y esto es lo que quisiera comentar a vuelapluma.

1. ¿Cuál fue esa actitud? La misma que la Biblia atribuye a Dios cuando dice: "He visto la tribulación de mi pueblo y he oído sus clamores" (Ex 3,7). Medellín será un punto de referencia constante porque es uno de los pocos momentos, en el segundo milenio cristiano, en que la jerarquía de la Iglesia ha tenido ojos y oídos para el clamor del pueblo oprimido: "Un sordo clamor brota de millones de hombres, pidiendo... una liberación que no les llega de ninguna parte... El episcopado latinoamericano no puede quedar indiferente..." (Pobreza de la Iglesia, 1). 
Tan serio es esto que no cabe negar el intento posterior de la jerarquía eclesiástica por dar marcha atrás de esa actitud. Con la excusa de que "había habido lecturas equivocadas", de que se había malentendido a Medellín, la jerarquía y un sector de teólogos han intentado sencillamente desoír ese clamor y volverse a otros clamores (culturales, tecnológicos, de seguridad... o simplemente al clamor de los poderosos de la tierra), que pueden ser enteramente legítimos y a los que todo el mundo debe prestar atención, pero que no son el clamor que Dios dice escuchar y, por tanto, el que preferentemente debe escuchar la jerarquía eclesiástica.

En Medellín, en cambio, la jerarquía eclesiástica hizo verdad por una vez, y para que sirva de referencia perpetua (y no sé si también de vergüenza posterior), lo que había dicho el Vaticano II, en uno de sus párrafos más famosos: que "los gozos y las esperanzas, las tristezas y las angustias... sobre todo de los pobres y de los que sufren", son a la vez gozos y esperanzas, tristezas y angustias de la Iglesia. En Medellín fue verdad que "la Iglesia se siente íntima y realmente solidaria del género humano y de su historia" (GS 1, 1).

Naturalmente, eslo tuvo un precio. Mons. Romero, Mons. Gerardi y Mons. Angelleli. Tres obispos mártires en sólo treinta años, los tres con connivencias "oficiales" y los tres en países católicos, son una cosa inaudita. Pero es bueno añadir que esos tres obispos no son más que la punta del iceberg de una legión incontable ya de "discípulos de Cristo" (GS 1, 1), que hicieron suyas las tristezas y las angustias de los pobres de la tierra. No es de extrañar, porque es humano, que luego de ello buena parte de la jerarquía haya preferido hacer suyos los gozos y las esperanzas de aquellos hombres que le dan a ella seguridad y que imponen paces de cementerio, que no son fruto de la justicia, sino del miedo o la impotencia...

Es comprensible porque somos humanos. Lo que no es aceptable es que se pretenda justificar ese cambio de óptica - lan conırario al evangelio- apelando al "orden" y a la "religión"; como si no quedara claro en el evangelio que el orden se hizo para lodos los hombres y no los hombres para el orden (cfr. Mc 2, 27), o que Dios quiere misericordia y no "religión" ( $c f r$. Mt 9, 13).

2. Y una segunda cosa merece destacarse, que se deriva de la anterior. Al aceptar esa óptica que es la del Dios biblico, y que está revelada en el Exodo, en el canto de María y en inconlables palabras de Jesús, Medellín reencontró el verdadero lenguaje sobre Dios. Ese lenguaje que la Iglesia busca hoy también, porque sin él no tiene nada que comunicar, pero prefiere buscarlo sólo en la melafísica, en la intimidad, en la seguridad del orden, o en el enorme anhelo del corazón humano (tan falsificable por otra parte), convirtiendo todos esos campos legítimos en una especie de auriculares potentes y privados, donde se escucha otra música que impide escuchar el clamor de los oprimidos de la lierra, que es la "primera voz" con que habla Dios. 
Después de Medellín, en esta Europa desde la que redacto esta nota, casi sólo la voz solitaria de un J. B. Metz y de su escuela siguen insistiendo en que hemos desfigurado de raíz el lenguaje sobre Dios, por intentar hablar de él al margen del sufrimiento humano. Como Metz no se ha cansado de enseñar, el lenguaje sobre Dios de la tradición bíblica es claramente un lenguaje con un flanco de sensibilidad ante el dolor, sobre todo ante el dolor injusto inflingido por la obra del hombre. Es un lenguaje roto por la pregunta inolvidable y sin respuesta de la teodicea. Pregunta que no liene una respuesta, sino sólo una nueva pregunta para todas nuestras respuestas. Es un lenguaje sobre Dios para el que la historia no es simplemente historia de los vencedores sino, ante todo, historia del sufrimiento, un lenguaje que, precisamente por eso, está históricamente concentrado en la memoria passionis sin la cual la memoria resurrecrionis cristiana se convierte en un puro milo de los vencedores.

Olvidar eslo en un mundo en el que, en un bloque, se ha pasado del materialismo histórico al materialismo histérico $y$, en el olro, se sigue el consejo del sabio Nietzsche de que, después que el viejo Dios ha sido eliminado, cada uno de nosotros desea serlo él, está volviendo irrelevante al cristianismo.

La jerarquía eclesiástica no debería olvidar (ni la jerarquía ni ningún cristiano, pero ahora me dirijo expresamente a ella, porque ella fue la que habló en Medellín) esa etimología que no sé si es cierta semánticamente pero lo es teológicamente, que afirma que credere se deriva de cor-dare (creer viene de "dar el corazón"). Porque si en vez de dar el corazón preferimos "defender el bastión", no haremos más que confundir la mayor seguridad propia con la mayor gloria de Dios (juego de palabras que, en mi humilde opinión, define muy bien la actual situación de la cúpula eclesiástica). Mientras que si Dios nos concede creer -en el sentido de cor-dare - nos encontraremos - junto con mil conflictos y problemas - con aquella constatación que hacía ingenuamente un discípulo acabado de Medellín “los cambios necesarios dentro de la lglesia, en su pastoral, la educación, la vida sacerdotal y religiosa, en los movimientos seglares, que no habíamos podido realizar mientras nuestra mirada sólo esıaba fijada en la lglesia, los realizamos ahora que nos dirigimos a los pobres" (Mons. Romero).

3. Esto es todo lo que tengo que decir, pero quizás sea obligado concretar un poquito más. Medellín parece hablar muy poco de Dios y, cuando lo hace, se trata muchas veces de citas. No es posible hacer aquí un estudio, sino sólo escoger algunos textos que serán, sin duda, fruto de la selección personal, porque brotan más del recuerdo que del análisis, pero que marcan una dirección.

3.1. Para comenzar, Medellín advierte contra una religiosidad "en la que Dios es respuesta a todas las incógnitas y necesidades del hombre" (Pastoral popular, 2) y que parece ser la que hoy rebrola entre sectas y postmodemidades. No la rechaza del todo, pero sí advierte que la Iglesia debe evangelizar esa religiosidad "descubriendo en ella la secreta presencia de Dios" (ibid., 5). Completa esta 
advertencia con la constatación de que "allí donde se encuentran injustas desigualdades sociales, políticas, económicas y culturales, hay un rechazo... del Señor mismo" $(P a z, 14)$. No se puede decir con más sencillez que en toda América Latina y en las relaciones intemacionales de los pueblos "hay un rechazo del Señor mismo", por más culto que se le quiera dar, y por más cristiano que se pretenda ser.

3.2. En segundo lugar, Medellín enseña que para conocer a Dios es preciso "conocer al hombre" (Conclissión, 1), entre otras razones porque, en este conocimiento Dios aparece como "la Fuente y el Fin de los valores supremos" (ibid., 6). Para conocer a Dios es indispensable además "conocer su Voluntad", en lugar de querer especular los misterios de su Ser, como si Dios pudiera ser dominado por el hombre.

3.3. Ahora bien, es voluntad de Dios "la unidad profunda que existe entre el proyecto salvífico de Dios realizado en Cristo y las aspiraciones del hombre: entre la historia de la salvación y la historia humana" (Catequesis, 4). Además, "según la volunlad de Dios los hombres deben santificarse y salvarse no individualmente sino constituidos como comunidad" (Pastoral popular, 9); la voluntad de Dios es la comunidad humana en la historia; y en el esfuerzo por esa comunidad accede el hombre a Dios. Por eso Medellín recordará en su mensaje a los pueblos que ha hablado asi "por fidelidad a ese plan divino".

3.4. Por eso también, Medellín enseña que "el Espíritu de Dios impulsa" al cristiano "a buscar una relación más profunda con Dios, con los hombres y con las cosas" (Justicia, 4), sin que sea posible eslablecer ahí ninguna separación. Por eso exhorta a los laicos a "entregarse a Dios en el servicio de los hombres" (Laicos, 17).

3.5. Y finalmente, también como consecuencia de lo anterior, Medellín suele concebir la relación del hombre con Dios mucho más en términos de "nosotros", que meramente en términos del "yo". Hay aqui una profunda coincidencia inconsciente con el Padrenuestro de Jesús, que no nos enscña a relacionarnos con Dios como "yo" (eso ya le sale a cada uno sin que nos lo enseñen), sino como "nosotros". Y esto se concreta en actitudes bien visibles: por ejemplo, la voluntad de la Iglesia de "acoger positivamente la pluralidad en la unidad, evitando erigir la uniformidad como principio a priori" (Liturgia, 7). Es decir, al revés de lo que suele ser la práctica eclesiástica habitual. $O$ el modo de tratar a los presbíteros que dejaron su ministerio: en lugar de medirlos con la Ley, "les decimos que los sabemos marcados con el sello del sacerdocio y que los respetamos como hermanos amándolos como hijos" (Sacerdocio, 30).

3.6. Se puede entender ahora por qué Medellín designa a la lglesia constantemente (y casi únicamente) como "pueblo de Dios", siguiendo al Vaticano Il. Contra los que creen ver en esá designación una "reducción sociológica", es 
preciso decir que esa designación no afirma simplemente algo sobre la Iglesia, sino que, sobre todo, dice algo sobre Dios. Al igual que ocurre con el texto de Mateo 25, 31ss. Que es ante todo un tex10 "sobre Dios".

En conclusión, no puedo ni sé decir, qué es lo queda o quedará de Medellín. Lo que sí me parece es que Medellín nos ha dejado planteado, otra vez, el problema del Dios verdadero, contra todos los falsos dioses. Y ello no es poco. Porque además, forma parte de la tradición religiosa judeocristiana, la doliente constatación de que a los hombres "nos gustan más" los dioses falsos.

\section{Comentarios a Medellín}

\section{Pedro Trigo, Centro Gumilla, Caracas.}

1. Si nos tomamos la molestia de leer desapasionadamente los documentos de Medellín, advertiremos ante lodo su buen espírilu, su lono constructivo, su intrépida esperanza y su fe firme y lúcida en los que habitamos en América Latina. Pero lo que a mí más me impresiona es que es un discurso con sujeto, es decir, que lo que dice a la sociedad de la que forma parte se lo dice también, y muy pormenorizadamente, a la lglesia que representa.

Esta correspondencia entre las propuestas de reforma eclesial y las de compromiso social da la medida de la verdad y trascendencia de esta asamblea episcopal. Hablar a otros sin hablarnos a nosotros mismos es un hablar farisaico (Mt 23, 4), que elude culpablemente el propio sujeto y carece por eso de peso y eficacia. Asienta desde la Introducción: "Esta asamblea fue invitada a tomar decisiones y a establecer proyectos. solamente si estábamos dispuestos a ejecutarlos como compromiso personal nuestro, aun a costa de sacrificio" (n. 3). Creo que esto ha sido verdad. Quienes hicieron Medellín pusieron efectivamente en práctica esas decisiones. Más aún, fueron capaces de plasmarlas porque ya estaban comprometidos en esa dirección. Y la fecundidad de Medellín estriba en que todo lo que de significativo y fecundo se ha ido dando en estos treinta años en nuestra Iglesia ha transcurrido por los cauces que trazó magistralmente esa conferencia de obispos.

2. Desde este punto de vista, quisiera recalcar como absolutamente válido e inspirador el plan tan concrelo y orgánico de reforma de la lglesia. Muchas cosas puede hacer y está haciendo la Iglesia en favor de América Latina, pero creo que su mayor aporte consistiría en su propia reforma. Ella es una de las instiluciones fundamentales del continente. Su transformación, según los lineamientos de Medellín, incidiría profundamente en otras instituciones y arras- 
traría a una parte considerable del pueblo y a un número significativo de profesionales e intelectuales. Además de la fecundidad histórica de este cambio, él es un requerimiento ineludible de fidelidad. Medellín es claramente la aplicación del concilio a la Iglesia latinoamericana. Y no cabe duda de que Dios nos pide de un modo perentorio que recibamos el concilio, es decir que lo asimilemos creativamente, desde nuestra situación.

Esta conversión tiene dos manifestaciones básicas. La primera es el cambio de destinatario privilegiado, de condición social y de ubicación. Medellín apuesta por una institución eclesiástica realmente pobre, ubicada no en la cúpula social sino entre los de abajo y cuyo destinatario preferencial sean los pobres. A ello dedican un capítulo entero (el capítulo 14). Pero el carácler sistemático de esta orientación se echa de ver en que está decisivamente presente en los demás $(3,11 ; 5,15 ; 10,13 ; 13,11)$. Ya en el Mensaje introductorio insisten en que la necesidad de acabar con la separación entre fe y vida "nos exige vivir una verdadera pobreza biblica que se exprese en manifestaciones auténticas, signos claros para nuestros pueblos. Sólo una pobreza asi trasparentará a Crislo". Además de estos signos, proponen reformas estructurales, que institucionalicen esta opción. Ante todo una redistribución "de los esfuerzos y del personal apostólico que dé preferencia efecliva a los sectores más pobres" $(14,9)$. Además, comprendiendo que el sistema arancelario es la fuente de las desigualdades económicas del clero y de la imagen de lucro y aun de riqueza de la Iglesia, proponen reemplazarlo por olras formas de cooperación económica, desligadas de los sacramentos (14, 13), y llegar a una equidad que exprese la fratemidad de la comunidad sacerdotal, mediante un fondo común diocesano y aun nacional para el sustento y seguridad social del clero $(14,15)$. En resumen, "que se presente cada vez más nítido en Latinoamérica el rostro de una Iglesia auténticamente pobre, misionera y pascual, desligada de todo poder temporal y audazmente comprometida en la liberación de todo el hombre y de todos los hombres" $(5,15)$.

La segunda concreción fundamental de la conversión que Medellín delinea va en la dirección de una Iglesia comunitaria, que institucionalice la participación. La participación arranca desde el nivel de la célula básica de la Iglesia que es la comunidad. No sólo se pide a la Iglesia existente reconfigurarse comunitariamente, sino que la evangelización y la catequesis deben tener como objetivo la constitución de comunidades cristianas. La catequesis "no puede limitarse a las dimensiones individuales de la vida. Las comunidades cristianas de base, abierlas al mundo e insertadas en él, tjenen que ser el fruto de la evangelización, así como el signo que confirma con hechos el Mensaje de Salvación" $(8,10)$. En ellas ha de encontrar ante todo el cristiano la vivencia de comunión a la que ha sido llamado por Dios. "La comunidad cristiana de base es así el primero y fundamental núcleo eclesial que debe, en su propio nivel, responsabilizarse de la riqueza y expansión de la fe, como también del culto que es su expresión. Ella es, pues, célula inicial de estructuración eclesial, y foco de la evangelización, y 
acłualmente factor primordial de promoción humana y desarrollo" $(15,10)$. Desde ese punto de partida piden "hacer de la partoquia un conjunto pastoral vivificador y unificador de las comunidades de base. Así la parroquia ha de descentralizar su pastoral" $(15,13)$.

A nivel más global, la salud del cuerpo eclesial depende del equilibrio de los flujos comunicacionales ascendentes y descendentes entre la base y los paslores $(15,8)$. Por eso, se proponen "nuevas estructuras en la Iglesia que institucionalicen el diálogo y canalicen la colaboración entre obispos, sacerdotes, religiosos y laicos" (Mensaje). Por de pronto, los presbíteros "comparten con todo el Pueblo de Dios el mismo misterio y la misma y única misión salvadora". Por eso, deben mantener con los laicos un diálogo no ocasional, sino "constante e institucional". Lo mismo dígase con respecto a las religiosas y a los religiosos no presbíteros" $(11,16 ; 12,14)$. Asimismo, debe configurarse el presbiterio como cuerpo fraterno que incluye al obispo. "De ahí se deduce, como consecuencia inevilable, la íntima unión de amistad, de amor, de preocupaciones, intereses y trabajos, entre obispos y presbíteros" $(11,14)$. Una manifestación fundamental de esta solidaridad es "el diálogo, en el que haya mulua libertad y comprensión, tanto con respecto a los asuntos a tratar como a la manera de disculirlos" (11, $15,23-24)$.

En este diseño participativo, el documento sobre Pastoral de Conjunto (n. 15) es especialmente paradigmático. Recoge orgánicamente tanto el espíritu que anima a esta dimensión cristiana, como los cauces institucionales que lo expresan.

Queremos insistir en que esta participación no es meramente funcional, sino que arranca del misterio de la Iglesia, que es comunión de vida y de misión. Una comunión absolutamente personalizada, que sólo puede darse desde la autenticidad de cada individuo; pero a la que también contribuye todo el cuerpo social: "toda la comunidad cristiana, unificada y guiada por el obispo, es responsable solidariamente del desarrollo vocacional, tanto en su aspeclo fundamental cristiano, la vocación en general, como en sus aspectos específicos: vocaciones sacerdotal, religiosa y laical" $(13,23)$. "Por lo mismo es necesaria una pastoral juvenil que, para ser plenamente auténtica, debe llevar a los jóvenes, por medio de una maduración personal y comunitaria, a asumir un compromiso concreto ante la comunidad eclesial en algunos de los llamados estilos de vida" $(13,25)$.

Como se ve, Medellín esboza un cuerpo social en el que la individuación crece directamente proporcional a la participación solidaria. Por eso, la socialización no se concibe como internalización de pautas preestablecidas, emanadas desde el poder, sino como la ayuda que la comunidad presta a cada miembro para que descubra su puesto personal en ella y se capacite para ocuparlo creativamente. La pastoral vocacional no tiene ya como objetivo primordial asegurar la continuidad institucional, sino lograr que el cuerpo eclesial completo (tanto en su expresión básica común como en sus diversos servicios y oficios) mantenga 
dinámicamente su condición carismática, es decir que no sea una masa informe, sino un cuerpo vivo, altamente personalizado.

La consecuencia de esta dinámica es una Iglesia de comunidades cada vez más internamente diferenciadas y mutuamente referidas. Esta catolicidad, que excluye por igual la uniformidad y la dispersión, se refleja en todos los ámbitos, hasia los más delicados de la doctrina y la liturgia: "Con un sincero intercambio de colaboración, debemos guardar la unidad de la fe en la diversidad de formas" $(8,8)$. "Acoger, por tanto, positivamente la pluralidad en la unidad, evitando erigir la uniformidad como principio" $(9,7)$.

3. Nos hemos detenido en este punto porque pensamos que sólo una Iglesia así puede proponer con autoridad la construcción de una sociedad participativa y contribuir eficazmente a que se encamine en esa dirección. Sólo un lglesia que incluye en sí como sujetos, e incluso como sujetos privilegiados, a los pobres puede denunciar la marginación de las grandes masas. Con esta observación cornienzan los documentos que analizan, en sus diversos aspectos, la situación del continente $(1,1 ; 2,2 ; 3,2 ; 4,3 ; 5,1 ; 10,2 ; 15,1)$. De ahí que desde el Mensaje inicial proponga "inspirar, alentar y urgir un orden nuevo de justicia que incorpore a todos los hombres en la gestión de las propias comunidades". En el campo político proponen la "creación de mecanismos de participación y de legítima representación de la población, o si fuera necesario, la creación de nuevas formas" $(1,16)$, pues constatan que actualmente existen "sistemas que atentan contra el bien común o favorecen a grupos privilegiados" (ibid.), dando como resultado "la consolidación de instituciones puramente formales" $(1,16)$. Muy certeramente insisten, como punto de partida para una participación política regional y nacional, "en la necesidad de vitalizar y fortalecer la organización municipal y comunal" $(1,16)$. En el campo económico las genuinas representaciones de los trabajadores deberían participar no sólo en el nivel de la producción, sino también "en los niveles políticos, sociales y económicos donde se toman las decisiones que se refieren al bien común" $(1,12)$.

Como ni los modelos tradicionales ni las propuestas actuales de desarrollo contemplan la participación ciudadana y menos aún la de los sectores populares, los documentos insisten en que se den oportunidades educativas a todos, "en orden a la posesión evolucionada de su propio talento y de su propia personalidad, a fin de que, mediante ella, logren por sí mismos su integración en la sociedad, con plenitud de participación social, económica, cultural, política y religiosa" $(4,11)$.

Para eso cuentan con el apoyo de la juventud. En esos años de explosión mundial estudiantil, la juventud aparece "como un nuevo cuerpo social". Y entre sus cualidades destacan que "busca participar activamente, asumiendo nuevas posibilidades y funciones dentro de la comunidad latinoamericana" $(5,1)$.

Pero como los obispos son conscientes de la marginación popular, proponen también una "educación de buse", dirigida a los adultos, no sólo para alfabetizar, 
sino para "capacitar al hombre y convertirlo en agente consciente de su desarrollo integral" $(4,16)$.

Para Medellín, la solución a los problemas no es la confrontación. Los cambios violentos de estructuras serían ineficaces y no conformes con la dignidad del pueblo, que reclama que "las transformaciones necesarias se realicen desde dentro, es decir, mediante una conveniente toma de conciencia, una adecuada preparación y esa efectiva participación de todos" $(2,15)$.

En esta circunstancia de oposición a las necesarias transformaciones por parte de la mayoría de las élites, los obispos insisten en que hay que resistir a la tentación de la violencia y por el contrario ansían "que el dinamismo del pueblo concientizado y organizado se ponga al servicio de la justicia y de la paz" (2, 19). “La justicia y, consiguientemenle, la paz se conquista por una acción dinámica de concientización y de organización de los sectores populares, capaz de urgir a los poderes públicos, muchas veces impotentes en sus proyectos sociales sin el apoyo popular" $(2,18)$.

Pero como el pueblo no tiene experiencia de participación en el área política y en muchos casos tampoco en el de la producción y como existen tan formidables obstáculos, es imprescindible comenzar por la organización de las propias comunidades. En ellas llegarán a alcanzar, "a través de estructuras territoriales y funcionales, una participación receptiva y activa, creadora y decisiva, en la construcción de una sociedad" $(1,7)$. Este plano de lo societal es el decisivo: "Es necesario que pequeñas comunidades sociológicas de base se desarrollen para establecer un equilibrio frente a los grupos minoritarios, que son los grupos de poder" $(1,20)$. La propuesta es, pues, establecer un equilibrio dinámico entre los flujos comunicativos y de acción ascendentes y descendentes. Pero como el punto de partida es el dominio casi incontrastable de los flujos descendentes, los obispos reclaman la urgencia de que la base se articule desde sí misma. Por eso, estimamos que la propuesta que puede resumir el aporte de Medellín al desarrollo humano del continente es la siguiente: "Alentar y favorecer lodos los esfuerzos del pueblo por crear y desarrollar sus propias organizaciones de base" $(2,27)$.

4. El reto que lanza Medellin a la teología es, ante todo, cómo fundamentar y sistematizar la unidad profunda que existe entre la historia de la salvación y la historia humana, sin caer en confusiones o en identificaciones simplistas. Dicho a nivel sotereológico, cómo explicar el paso de Dios que salva cuando se avanza en humanidad, tanto superando Jo inhumano como encaminándose hacia cotas cada vez más altas de humanidad. Habría que profundizar de un modo particular en la articulación interna entre esos distintos niveles que configuran la vida humana como un todo intemamente diferenciado, pero mutuamente referido y buscando dinárnicamente su unidad jerarquizada. Formulado de olra manera, se trataría de explicar la relación entre hisloria y escatología y el papel que juega en ella el paradigma de Jesús y su Espíritu. Esta problemática, tan lípicamente 
conciliar, está planteada en Medellín, al proponer al continente el desarrollo integral, entendido fundamentalmente como desarrollo humano, como un proyecto holístico, integrador. Para Medellín no caben identificaciones simplistas ya que es el primero en subrayar la situación de pecado, el pecado estructural, es decir, el hecho de que un orden social rechace como tal al Señor. Esta afirmación de Medellín dialectiza la dirección encamatoria del concilio y la conduce hasta la pascua. Así, pues, habría que pensar esta unidad desde el reverso de la historia, aunque sin desechar los bienes civilizatorios y culturales en los que ha de reconocerse la acluación del Espíritu. Pero ha de sostenerse no sólo que el sujeto de ese desarrollo humano ha de ser la humanidad como un todo, rechazando absolutamente la exclusión, sino que el sujeto privilegiado son los de abajo, y que sólo desde ellos puede arrancar un proyecto que sea en verdad ecuménico y biófilo, es decir, realmente humanizador.

El otro gran tema a pensar es el de la configuración de una Iglesia de comunión y participación. Desde la fundamentación hasta el diseño concreto, pasando por el análisis teológico de las diversas figuras históricas. Ya hemos indicado las pistas que ofrece el documento.

\section{Historias proféticas para recordar Medellín}

\section{Dolores Aleixandre RSCJ, Universidad Pontificia Comillas.}

Junto a los canales de Babilonia, un grupo de judíos exilados se había reunido, como de costumbre, para un monótono rilo de exequias. Tenían la esperanza quebrada como una caña, extinguida como la llama de un candil y desmoronada como las murallas de Jerusalén.

Una vez más, se disponían a evocar con voz nostálgica el recuerdo de Sión y a maldecir a los que los habían deportado, cuando les sorprendió la propuesta de uno de ellos al que algunos tenían por profeta.

- Escuchen, ¿por qué no traen también a nuestra memoria viejas historias de profelas? También ellos vivieron liempos duros como los nuestros y quizá podamos aprender de ellos de dónde sacar ánimo para seguir esperando... Déjenme contarles de nuevo dos de sus historias, aunque seguramente las han oído narrar, lo mismo que yo, muchas veces.

El grupo se quedó perplejo ante algo que introducía una novedad insólita en sus reuniones; pero ya el profeta comenzaba a hablar, sumergiéndolos en la magia de la narración: 
Corrian tiempos dificiles para Juda: los reyes de Siria y de Israel se habian aliado contra Juda y habian sitiado Jerusalén. Isaías habia intervenido pidiendo a Acaz que no se dejara vencer por el miedo. Pero el rey, después de buenas palabras y gestos de estudiada compunción, habia enviado embajadores a Asiria pidiendo auxilio al emperador. Jerusalén se había convertido en un hervidero de rumores: se daba ya por segura la alianza, y se comentaba el fracaso de Isaías por evitarla. El rey prefería una seguridad efimera y llena de trampas, a confiar en las alas del Emmanuel, como le instaba el profeta.

Isalas supo entonces que habia sonado para él la hora de comunicar la Palabra de otra manera. Llamó a sus dos hijos y a sus discípulos e hizo un gesto extraño: introdujo el rollo que contenían sus palabras en un cántaro de barro, lo sello y dijo a los que lo rodeaban:

"Guardo selladas estos instrucciones, ustedes son su garantía; y voy a per. manecer aguardando al Señor, aunque nos oculte su rostro. Nosotros nos convertimos ahora en signo y testimonio para Israel, de parte del Señor de los ejércitos, que habito en el Monte Sión".

Comenzó a partir de entonces un largo periodo de forzoso silencio. Pero uquel profeta, que ya comenzaba a envejecer, junto con el exiguo grupo de sus seguidores, sabian que eran testigos de una palabra que guardaba, como un tesoro escondido, aquél cántaro sellado. Y eso les daba fuerza para seguir esperandol.

El profeta continuó diciendo:

- La otra historia, la conocen también todos: es más reciente y para recordarla, los invito a trasladarse con la imaginación al patio de guardia en el que está detenido Jeremías, cuando ya la sombra Nabucodonosor se cernía sobre la ciudad. Escuchen:

El viento habia traído hasta el patio un puñado de cenizas, y Jeremías supo que era todo lo que quedaba de sus palabras, es decir, de la Palabra del Señor.

Se las habia ido dictando a Baruc, su secretario, y éste las habia escrito en un rollo de pergamino, pero de todo aquello no quedaba ni rastro; desde el otro lado del muro se escuchaban las carcajadas de los cortesanos de Joaquim, reunidos en torno al rey en las habitaciones de invierno, y celebrando el gesto real de cortar con un cortaplumas cada columna del rollo que leia el escriba, para arrojarlas después al brasero.

1. Cfr. Is $8,16-18$. 
"Es el final", pensó Jeremías y escondió con abatimiento la cabeza entre sus manos.

Pero aquella noche el Señor le dirigió la palabra, sorprendiéndole como de costumbre:

"Toma otro rollo y escribe en él todas las palabras que habia en el primero, quemado por Joaquin".

Jeremías lo hizo, y al concluir su dictado, Baruc le hizo ver que este segundo rollo contenía muchas más palabras que el primero.

$Y$ los dos se miraron en silencio, porque estaban empezando a comprender algo de la suerte de la Palabra, más fuerte que cualquier intento de silenciarla o de hacerla desaparecer2.

A concluir la segunda narración, en el grupo de exilados reinaba un silencio denso. Entonces volvió a escucharse la voz del profeta.

$-i$ No comprenden lo que quieren decirnos estos antiguos relalos? ¿No se dan cuenta del suelo que ponen debajo de nuestros pies? Hubo antes de nosotros muchos intentos de sofocar la palabra profética, pero fueron como la hierba de los tejados: se secó y se la llevó el viento. En cambio, la Palabra de nuestro Dios permanece para siempre.

Y voy a pronunciar entre ustedes palabras de consuelo?.

\section{Dos mil quinientos años después ( $y$ a treinta de Medellín)}

Si hay un adjetivo que refleja bien lo que supuso para toda la lglesia, no sólo para la latinoamericana, aquella segunda Asamblea del CELAM, es el de profética: en Medellín se captó la presencia de Dios en la historia y en la misión de la Iglesia; se miraron los acontecimientos desde la fe y desde la perspectiva de los pobres, se trató de desligar a la Iglesia de fardos de intereses y cálculos mundanos, se denunció todo lo que representa una conculcación de los derechos humanos.

Lo mismo que los Profetas, acuciados siempre por la pregunta de Dios ("¿Qué ves, Amós?", “¿Qué ves, Jeremías?"...), Medellín se asomó al mundo latinoamericano y pronunció palabras en relación con sus sufrimientos y sus esperanzas. Fue también capaz de ir más allá de lo que veía y oía, y apostó por la posibilidad de transformación de las situaciones. Habló de Dios y de la Iglesia desde una sensibilidad solidaria y cercana a situaciones extremas, las puso a dialogar con la Biblia, y de ahí nació su lenguaje teológico. Es esa una sabiduría

2. Cfr. Jer 36.

3. Is 40, 1-2. 
a seguir aprendiendo siempre por parte de la teología que, en palabras de Gustavo Gutiérrez, "no puede colocarse en un punto muerto de la historia para verla pasar. Si no tiene en cuenta la existencia humana, con sus complejas idas y venidas, el lenguaje sobre Dios sería como el juego de tenis sin pelota que presenta Antonioni en una de sus peliculas".

La situación del mundo, treinta años después, es sombría: aumento vertiginoso de los excluidos del sistema neoliberal, iniquidad de las leyes que rigen la economía, idolatría del provecho, ecocidio incontrolado, rearme creciente. El emperador de Asiria es ahora el mercado y con él se hacen toda clase de pactos. No parece que las palabras de Medellín hayan cambiado mucho la historia.

Por otra parte, en muchos sectores de Iglesia parece extinguido aquel soplo profético: surgen nuevos "braseros" de autoritarismos y prohibiciones, aumenta la intolerancia y el lenguaje de recriminación y de censura, existen demasiadas comunidades perplejas y desalentadas, demasiados teólogos silenciados, demasiadas mujeres heridas, demasiados sacerdotes frustrados. No parece que el talante de Medellín haya dejado mucha huella.

¿Se acabará aqui nuestra percepción de la realidad del mundo? ¿No estaremos necesitando escuchar palabras parecidas a las que atravesaron, como un martillo o como un fuego, a los profetas?

No vayas a creer que son tan pocos tus discípulos, lsaías: fijate en los grupos que en España ha ido tejiendo silenciosamente, a fuerza de gestos de paz, la posibilidad abierta de un futuro libre del terrorismo; mira a la gente que se concentra cada vez que hay un accidente con las pateras, y a tantos voluntarios entregando su tiempo y su energía en acciones solidarias.

Escucha la voz del grupo "Somos Iglesia" con ocasión de la polémica en torno a la ampliación de la ley del aborto, y su empeño en ulilizar olro lenguaje en el que se hable de "expreso", "puntualizo", "me duele", "observo", en lugar de: "condeno", "recrimino", “acuso...".

Presta atención a las voces del Consejo Mundial de las Iglesias, llamando a todas las Iglesias cristianas a comprometerse en el año 2000 a iniciar la preparación de un Concilio Cristiano Universal.

Mira la búsqueda de muchas comunidades que reflexionan sobre el tipo de liderazgo para el próximo obispo de Roma, que parece requerir nuestra época.

Recuerda el esfuerzo de tantos teólogos y teólogas vueltas hacia los sufrimientos y esperanzas de sus hermanos y hermanas, convencidos de que, como decía Medellín, "para conocer a Dios es necesario conocer al hombre"?4.

4. "Presencia de la Iglesia en la aclual transformación de América Latina" n. 1. 
Atiende a la provocación de estas propuestas:

No dejar de creer que es posible organizar el mundo de otra manera. La "imposibilidad" actual es simplemente fáctica: no hay voluntad de hacerlo, estamos dominados por quienes no quieren hacerlo. Pensar que no hay alrernativa o que es imposible sería aceptar el "final de la historia", el fracaso de Dios y la derrota de los humanos. No esperar a que fracase el neoliberalismo para atraverse a denunciar los estragos que provoca y su carb́cter antiético esencial. La lucidez proférica consiste en declararlo ahora, no cuando, quizo muy pronto, sean los mismos directores del Fondo Monetario Internacional (FMI) o del Banco Mundial quienes reconozcan su fracaso. Cuando esto ocurra, no faltarán profetas oportunistas que corearán lo que ahora, sumidos en un mar de perplejidades, no logran ver. Ser hoy, en ese sentido, continuadores de aquellas heroicas excepciones que se atrevieron a enfrentarse con el tráfico de esclavos de los siglos XVI-XIX cuando nadie, ni en la sociedad ni en las iglesias se atrevió a negar la supuesta legitimidad evidente del sistema esclavista dominantes.

Queremos salvaguardar la memoria de nuestras iglesias y nuestros pueblos y nos sentimos responsables de una herencia de siglos de luchas y mártires que no podemos olvidar. Caminamos con los muchos hermanos y hermanas que, en nuestra América, en todo el tercer mundo y en el primer mundo solidario, contestan con esperanza el fatalismo del sistema único que nos quieren imponero.

¿No reconoces en esta postura la de aquellos que, junto a li, fueron signo y presagio y mantuvieron vivo el recuerdo de las palabras que encerraba tu cántaro sellado?

Fijate bien, Jeremías, ¿no será que tienes ojos que no ven, oidos que no oyen y un corazón tan embotado que sólo percibes el ruido de la violencia, la destrucción y el odio?

Mira los almendros, Jeremías, ¿no ves ninguna rama florecida? iNo te das cuenta del murmullo de innumerables gestos de amor, de fiesta compartida, de fortaleza silenciosa que brola de los lugares de abajo, del mundo de los excluidos, de donde parece que no podría surgir más que la amargura o la tristeza?

¿No has oído "el grilo de Riobamba", fruto del encuentro de obispos, teólogos y pastoralistas en memoria de los diez años de la muerte de Leónidas Proaño? Porque los que estaban allí reunidos se sentían convocados acuméni-

5. "Propuestas para la coyuntura neoliberal", Agenda larinoamericana, 1998.

6. "El grito de Riobamba". 
camente por el Dios del Exodo y de la pascua, que escucha siempre el clamor de su pueblo, en los caminos de liberación y de vida.

Queremos construir día a día la Iglesia que soñamos como pueblo de Dios, con la Biblia hecha vida en las comunidades eclesiales de base, con las pastorales sociales, en la creatividad fiel al evangelio. Queremos que éste sea el modo de vivir y de ayudar a vivir en nuesiras respectivas iglesias y palses, el verdadero jubileo permanente que instauró Jesús de Nazaret (...) compartiendo fraternalmente una paz con justicia y dignidad, en la satisfacción de las más grandes reivindicaciones: tierra, salud, alimentación, educación, comunicación y trabajo...?

$Y$ en los gestos y palabras de tantos hombres y mujeres que, desde las nuevas Babilonias, siguen luchando, orando y esperando ino siguen resonando las palabras de ánimo de aquel profeta del destierro?

Porque sólo desde una esperanza como la suya, la misma que alienta los documentos de Medellín, se puede continuar apostando por "el potencial humano, más valioso que las riquezas escondidas en el suelo de nuestra tierra", y proclamando una confianza inquebrantable en la amorosa presencia del Dios de Jesús, el liberador de los pobres, Padre y Madre de la familia humana.

\section{Medellín 1968-1998 en perspectiva evangélica}

\section{Jürgen Moltmann, Universidad de Tübingen.}

1. El documento de la conferencia latinoamericana de obispos de Medellín, 1968, fue un acontecimienlo eclesial histórico y único. En concrelo, fue el acicate eclesial para el desarrollo de la teología de la liberación. En aquellos inicios, los teólogos de la liberación estaban en armonía con su Iglesia, y sólo más adelante, en 1984 y 1985, aparecieron los conflictos con la Congregación de la Fe. Estos conflictos, sin embargo, carecen de fundamento si se ve la teología de la liberación en la línea de los documentos de Puebla (1979), Medellín (1968) y Gaudium et Spes (1965). De hecho, existe una línea direcla y clara desde Gaudium et Spes -que pasa por Medellín y Puebla - hasta la teología de la liberación.

En mi opinión, tres son los factores que hicieron posible la irrupción sin precedentes de la Iglesia católica en la irrupción más general del pueblo latino-

7. "Lenguaje teológico: plenitud del silencio", Páginas 137, 1996, p. 67. 
americano pobre: la teología de la liberación, el movimiento bỉblico católico y el movimiento de las comunidades de base.

Nosotros, en 1968, mirábamos con gran envidia a los teólogos latinoamericanos de la liberación, pues en ese mismo año, las luces se apagaron para Europa, lo que iba a durar 20 años: las tropas del pacto de Varsovia ocuparon Checosiovaquia y acabaron con el comunismo reformista, aquel "socialismo con rostro humano". De esta forma también llegaba a su fin el diálogo marxista-cristiano que había comenzado tan esperanzadamente tres años antes, $y$ en el que Johann Baptist Metz y yo habiamos elaborado nuestra "teología política". En 1968 caía asesinado, en Memphis, Alabama, el líder y profeta del movimiento negro pro derechos humanos, Martin Luther King Jr. En 1968 aparecía también la encíclica Humanae vitae con la prohibición del control artificial de la natalidad, lo que costó sus cátedras a muchos teólogos calólicos reformistas. Para nosotros el año 1968 significó el final de muchas esperanzas, y también el principio de una fuerte oposición contra la guerra de Vielnam, contra el endurecimiento del bloque oriental, contra el deterioro ambiental y el rearme nuclear y contra el retroceso intraeclesial con respecto al Concilio Vaticano Il y al movimiento ecuménico.

2. Visto teológicamente, con Gaudium et Spes, Medellín y Puebla, y con la teología de la liberación comenzó la traducción del viejo esquema tomista de "naturaleza-gracia" a un esquema modemo de "historia-escatologia". Cuando la realidad en la que viven, sufren y creen los seres humanos ya no está determinada por la naturaleza, sino por la historia, entonces, la teología de la gracia y de la fe tiene que introducirse en la "dinámica de la historia". En lugar de una "teología natural" aristotélica aparece la teología histórica de los "signos de los tiempos", como dice Gaudium et Spes. Estos signos fueron leídos por Medellín de esta manera: "estamos en el umbral de una nueva época histórica de nuestro continente, llena de un anhelo de emancipación total, de liberación de toda servidumbre, de maduración personal y de integración colectiva" (Introducción, 4).

En Medellín, estos "signos de los liempos" latinoamericanos fueron interpretados como "un evidente signo del Espíritu (de Dios)" (Introducción, 4). Por tanto, la Iglesia tiene que estar presente ahi donde la espera el Espíritu de Dios en la historia. Tiene que introducir la dinámica propia de la gracia en esta dinámica de la historia de la liberación humana. Como lo muestra la teología de la liberación, esto acaece al comprender esta gracia de Dios no ya como "sobrenaturaleza", sino como la venida del reino de Dios. Con esto, la misma Iglesia se coloca en la perspectiva histórica y liberadora del "primer pueblo de Dios" y busca su propio camino, según el paradigma del éxodo de Israel: de la esclavilud a la tiema prometida de la libertad, en la que habita la juslicia de Dios. Asume la crítica política y las promesas de fuluro de los profelas de Israel y se comprende a sí misma como el "pueblo mesiánico" de Jesucristo. Lo que en el antiguo esquema de "naturaleza y gracia" se relacionaba con cielo y tierra. 
adquiere ahora su diámica propia en el nuevo paradigma de "historia y escatología". Así como en el antiguo esquema "naturaleza y gracia" se compenetraban mutuamente, asi se compenetran ahora historia y fururo (escatológico): presencia del futuro en la historia y de la historia en el futuro de Dios.

Esto supone que la escatología ya no es sólo la "doctrina de las cosas últimas", sino que es una doctrina de la esperanza presente, que experimenta la esclavitud a la luz de la liberación que ha de venir. Esta nueva escalología versa sobre el fuluro, que en la fuerza del Espíritu determina ya el presente, y no sobre mundos imaginarios e inúliles en un futuro lejano. En esle nuevo paradigma de la teología se encuentran los léblogos europeos y latinoamericanos en caminos paralelos. Nuestro "contexto vilal" (Siz im Leben), nuesiro locus theologicus o nuestro contexto y kairos son distintos: allá, en el tercer mundo, están los pobres que se hunden en la miseria que les deparan los ricos; aqui está el primer mundo, que busca protegerse económica, militar $-y$ ahora también policíacamente- de las migraciones de los pobres, especialmente de Africa. Vivimos en lados distintos de la injusticia global y buscamos un mundo común, que sólo puede ser construido sobre la justicia. ¿Existe un marco teológico común para ello? Treinta años después de Medellín sigue habiéndolo.

“Toda teología de la liberación sana, fecunda, está inmersa en la teología del reino de Dios", afirmó Gustavo Gutiérrez en su clásico libro Teologia de la liberación (1972), remitiéndose al mensaje de Jesús. De Jon Sobrino aprendemos que el "reino de Dios" representa, según el evangelio de Juan, "la plenilud de la vida", y por tanto, la vida plena, vivificada, lotalizante y en común. Esto nos conduce por sí mismo a la huella del presente y de las energías del Espíritu Santo. Este Espíritu fue llamado desde el principio "fuente de vida" (fons vitae) y "vida vivificante" (vita vivificans). En las energías del Espíritu de Dios, energias que liberan, que yerguen a los caídos y que vivifican a lo que está oprimido y proclive a la muerte, está ya presente toda la dinámica escatológica del reino de Dios.

Nosolros mismos podemos estar ya totalmenle presentes en la experiencia del Espíritu de Dios vivificador, sin tener que esperar con ansiedad lo que "todavía no" es. En la presencia del Espíritu de Dios tenemos que identificar el reino de Dios con la voluntad de liberación humana, puesto que en esa presencia experimentamos la fuerza mesiánica del instante vivido. "Miren ahora el momento favorable; miren ahora el día de salvación" ( 2 Cor 6, 2). Cuando en la fuerza liberadora del Espíritu los "demonios son expulsados" - y entiendo por "demonios" no fantasmas, sino los ídolos de la opresión política, económica y militar-, entonces, "es que ha llegado a nosolros el reino de Dios" (MI 12, 28).

Los teólogos latinoamericanos de la liberación no deben dejarse desviar de su "escatología presente" ni por el cardenal Ratzinger ni por los teólogos europeos. "Escatología presente" es, en verdad, experiencia y conocimiento del Espi- 
ritu Santo, en quien el reino venidero mostrará su poder de cara al presente, y en quien a nosolros - "los tristes y pobres - "se ha manifestado la vida" $(1 \mathrm{Jn} \mathrm{l}, 2)$.

Los mártires son siempre quienes nos dicen "de qué se trata en verdad en nuestro tiempo". Ellos son quienes nos muestran dónde y entre qué seres humanos nos espera el Cristo crucificado. Pienso en el arzobispo Oscar Amullo Romero y en Ignacio Ellacuría y sus compañeros, cuyas tumbas visité en la UCA de San Salvador. Los mártires nos dicen:

\author{
¿Cuándo, si no ahora? \\ ¿Dónde, si no aquí? \\ ¿Quién, si no nosotros?
}

\title{
30 años de Medellín
}

\author{
Johann Baptist Metz, \\ Viena.
}

Medellín inscribió la "opción por los pobres" en la conciencia de la Iglesia. Con todo, en los paises más pobres de nuestro mundo sólo será de provecho para los pobres cuando esa opción quede también registrada en la conciencia de la política, y ante todo, en la de la política de los países del así llamado primer mundo. Por esta razón, en estos últimos años, me he preguntado una y otra vez qué capacidad tiene entre nosotros esta "opción" para configurar la política.

La opción es, ciertamente, una protesta contra el pragmatismo de la libertad democrática, que se ha desvinculado de la memoria del sufrimiento y, así, ha caído "cada vez más" en una ceguera moral. $Y$ es que, en definitiva, una política democrática no puede consistir en la mera relación de interlocutores iguales entre sí, sino - más fundamentalmente y en total acuerdo con Medellín- en una nueva relación entre los que son distintos, y tiene centralmente en cuenta a los que están amenazados y son sacrificados.

Nuestra política occidental del concenso supone normalmente que las relaciones de mutua aceptación son estrictamente simétricas, pero esá concepción de la política no va más allá de la lógica de las relaciones del mercado, del intercarnbio y de la competencia. Sólo relaciones de aceplación asimétricas, sólo el volcarse de los unos que tienen vida a los otros que están amenazados y son sacrificados es lo que puede romper la violencia de la lógica del mercado en la polílica. 
En este énfasis en la asimetría no pocos verán un concepto demasiado exagerado de política. De hecho, sin embargo, sólo exige la exisłencia de la relación irrenunciable entre política y moral, ya que sin esa "implicación moral", la política -y la política mundial - sólo sería lo que hoy parece ser ya en buena medida: el rehén de la economía y de la técnica y de sus asi llamadas necesidades objetivas, en tiempo de globalización. En este sentido, Medellin puede hoy penetrar y hacer más aguda no sólo la conciencia de la iglesia, sino también la conciencia de la política, y de la política mundial.

\section{La visión liberadora de Medellín en la teología feminista}

\section{María Pilar Aquino, Universidad de San Diego, California.}

Cuando —en los años sesenta - tuvo lugar el acontecimiento de Medellín, la actual teología feminista crítica estaba sólo en sus comienzos. Esta teología surgió en la vida de la Iglesia como lenguaje creyente con el que mujeres y hombres articulamos críticamente la visión y la experiencia que tenemos de Dios dentro de nuestras luchas contra las múltiples formas de exclusión y de violencia producidas por la sociedad y la iglesia patriarcales. Inspirada por la leoría feminista contemporánea - que surge en los años cincuenta- y por la visión renovadora del Concilio Vaticano II, la leología feminisła arranca como discurso sistemático formal durante la década de los sesenta, en el contexto europeo y norteamericano. En esta misma década, con el impulso de la visión liberadora fundamental de Medellín y con la dirección transformadora de la emergente teología de la liberación, la teología feminista fue adquiriendo un lugar importante en las preocupaciones teológicas de las mujeres latinoamericanas.

En la década de los setenta, dichas preocupaciones fueron profundizadas lodavía más con la creciente toma de conciencia sobre la necesidad de enfrentar teológicamente el sexismo estructural, que marca a las culturas latinoamericanas, las múltiples formas de opresión que afectan a las mujeres y la posición subordinada de las mujeres en la lglesia, la teología y la tradición cristiana. La implementación a nivel mundial del programa "Década de la mujer", auspiciado por Naciones Unidas, y del programa "Comunidad de mujeres y hombres en la Iglesia", auspiciado por el Consejo Mundial de Iglesias durante los años setenta, constituyó un momento central, tanto en la determinación de las situaciones de injusticia vividas por la mayoría de las mujeres pobres y marginadas alrededor del mundo, como en la clarificación del compromiso cristiano en favor de una mayor igualdad y dignidad para estas mayorías. 
En los primeros años de los ochenta, la teología feminista adquiere cuerpo visible dentro de la Asociación Ecuménica de Teólogos y Teólogas del Tercer Mundo (ASETT) con la creación de la Comisión de Mujeres, que propuso la búsqueda de alternativas liberadoras frente al sexismo prevalente dentro de la ASETT y a la dominación patriarcal dentro de la sociedad, la lglesia, y la propia comunidad teológica mundial. La actividad teológica feminista crítica ha continuado su proceso de expansión en los ochenta y los noventa; llevada a cabo por mujeres y hombres del norte y del sur, ha dado nuevos perfiles a la inteligencia de la fe, tanto en método como en contenidos teológicos, y ha constituido un espacio fundamental para establecer un diálogo creativo entre la teología, las teorías feministas, la filosofia, los estudios raciales y de género y las ciencias sociales críticas contemporáneas.

La combinación de estos acontecimientos históricos y teológicos permiten ubicar a Medellín en el conjunto de las fuerzas sociales y eclesiales que, en la segunda mitad del siglo veinte, buscaron contribuir al establecimiento de una justicia mayor, que beneficie a los grupos oprimidos del mundo. Más aún, este contexto permitió comprender mejor el impacto de Medellin en los subsecuentes desarrollos teológicos que tienen como propósito central la eliminación del sufrimiento y la violencia causadas por los sistemas socio-económicos excluyentes, las culturas e iglesias sexistas, y la tolalidad de las relaciones sociales, articuladas por redes patriarcales de poder.

Este contexto tiene importancia primordial, sobre todo para hacer una valoración honesta y justa sobre lo que hoy hace falta mantener de Medellín en la Iglesia y la teología, y lo que sigue exigiendo de ellas. Sin este contexto, desde el desarrollo actual de la teología feminista crítica, cualquier mirada retrospectiva podría fácilmente caer en la simplificación de hacer notar el carácter sexista del discurso empleado por Medellín, el carácter reductivo del análisis que hace de la realidad latinoamericana al obviar las estructuras patriarcales dominantes, el carácter androcéntrico que marca la visión religiosa, cultural y teológica de Medellín, y el carácter jerárquico de la Iglesia al silenciar y ocultar la contribución de las mujeres a la vida de la Iglesia latinoamericana, desde sus comienzos hasta los grandes movimientos socio-eclesiales de los sesenta. Sin este contexto, la propia teología feminista carecería de honradez intelectual, al no reconocer que, en la década de los sesenta, los modelos conceptuales del feminismo crítico contemporáneo estaban sólo en proceso inicial de desarrollo. Consecuentemente, las categorías analíticas centrales del feminismo -tales como patriarcado, androcentrismo, sexismo, etc.- no eran incorporadas todavía de forma consciente, sistemática y comprehensiva ni en el discurso teológico, ni en las teorías políticas "liberadoras" de los sesenta, ni en la vida intelectual en general. En mi opinión, sólo tomando en cuenta este contexto, podemos apreciar la magnitud del impacto que Medeilín ha tenido en los desarrollos de la teología feminista crítica en América Latina. 
En mi apreciación de Medellín, encuentro que este evento y sus conclusiones dieron validez a las fuerzas sociales y eclesiales que buscan crear nuevas culturas y nuevos modelos sociales libres de exclusión y de violencia patriarcal. Medellín no sofoca estas fuerzas, sino que abre las puertas de la lglesia y de la teología a todo esfuerzo que contribuya al establecimiento de una mayor justicia social, "entendida como concepción de vida y como impulso hacia el desarrollo integral de nuestros pueblos" (Justicia 5). Para Medellín, la visión cristiana de la justicia incluye las luchas por mayor igualdad entre mujeres y hombres (Justicia 1); mayor conciencia de la contribución de la instrucción religiosa católica para pasar de la tradicional familia patriarcal hacia nuevos modelos de familia más avanzados, que promuevan una mejor distribución de responsabilidades y tareas entre mujeres y hombres (Catequesis 8, Familia 2); esfuerzos por cambiar las condiciones de la vida colidiana en favor de una mayor humanización, solidaridad y respeto de la dignidad humana (Justicia 9, Laicos 9); impulsar toda acción dinámica de concientización y de organización para enfrentar injusticias (Paz 18, Justicia 23), y el compromiso de la Iglesia por un nuevo orden social, basado en los principios de la justicia, la paz, la participación y la solidaridad ( $\mathrm{Paz}$ 20, Justicia 7). Tomando en cuenta estos aspectos, hoy día sigo creyendo que Medellín no sólo dio validez, sino que también potenció la visión feminista liberadora que hoy acompaña a numerosas comunidades cristianas a lo largo y ancho del continente y el Caribe. Como he sugerido en otra parte

en Medellín se encuentran ya en germen los ejes que luego van a ser explicitados e incorporados por la reflexión teológica y pastoral de las mujeres cristianas de América Latina. Estos ejes, en lugar de retraer el proceso de liberación de las mujeres, lo van a potenciar en la medida en que favorecen la adquisición de una conciencia lúcida y profunda sobre la misión e identidad de la mujer como Sujeto co-partícipe en la consirucción de la historia y la renovación de la Iglesia (La seología, la Iglesia y la mujer, Bogotá, 1994, p. 79).

Paso a mencionar ahora los aspectos más importantes que responden a las dos preguntas propuestas para este artículo. La primera es qué sigue siendo necesario de Medellín en la Iglesia y teología actuales. Desde mi punto de vista, el significado de Medellín para la vida de la Iglesia y para la actividad teológica en general es múltiple.

Primero, Medellín conlinúa siendo el acontecimiento histórico de mayor importancia en la Iglesia latinoamericana, en la segunda milad del siglo veinte. Su importancia proviene de la reinterpretación crítica que hace de las enseñanzas del Concilio Vaticano ll desde la realidad histórica latinoamericana y de la interpretación que hace de esta realidad como una siluación colectiva y estructural de injusticia y miseria, que exige de la Iglesia un compromiso transformador hacia mayor justicia y defensa de la dignidad humana. 
Segundo, Medellín sigue siendo el acontecimiento eclesial de mayor relevancia, debido a su visión de un nuevo modelo de Iglesia, que encama la dimensión transformadora del evangelio, que reconoce las dimensiones ética y sociopolítica de la misión evangelizadora, y que afirma la dimensión salvadora de la fe cristiana, entendida como praxis histórica de liberación.

Tercero, Medellín constituye un acontecimiento teológico de importancia mayor, porque afirma que el verdadero conocimiento de la fe acaece privilegiadamente desde la solidaridad activa con el mundo de los pobres y oprimidos, y con ello confirma un modo nuevo de hacer teología. El impacto de Medellín en las formas de vivir y de entender tanto la identidad de la Iglesia, como la naturaleza de la actividad teológica en el mundo contemporáneo, lo convierten en un acontecimiento de magnitud universal en cuanto entiende que la universalidad de la salvación cristiana es realizada primariamente desde las fuerzas socioeclesiales, que buscan humanizar y liberar a los grupos excluidos de toda situación opresora. Desde Medellín, la lglesia y la teología existen para potenciar esas fuerzas de salvación que ocurren en lo cotidiano de la realidad histórica. La Iglesia y la teología lienen el deber de acompañar solidariamente la fe vivida, pensada y celebrada por nuestras comunidades en su diario caminar hacia una mayor calidad de vida, y así redefine tanto sus fundamentos, como el propósito de su existencia.

En este sentido, la Iglesia y la teología actuales tienen todavía mucho que aprender de Medellín. Hoy en día, ya no es suficiente decir que la Iglesia y la leología latinoamericanas "acompañan solidariamente" la fe de la gente, si no existe una actitud de bienvenida y una apertura explícita a las fuerzas socioeclesiales que proponen eliminar el sufrimiento causado por la violencia patriarcal, especialmente la violencia hacia las mujeres y quienes dependen de ellas. La Iglesia y la teología actuales podrán hacer suyo el legado histórico, eclesial y teológico de Medellín sólo en la medida en que incorporen claramente la visión y el propósito de la teologia feminista crílica, que hoy acompaña a la fe vivida por innumerables comunidades cristianas. No faltará quien argumente que Medellín no adopta los marcos conceptuales del feminismo crítico, y con ello justificarán su negligencia en el compromiso con la actividad teológica feminista. Mi respuesta a este argumento es que Medellín no incorporó esos marcos por mera contingencia histórica, no por negligencia ni por mala voluntad. Basada en la innegable recepción que Medellín hace de la racionalidad crítico-liberadora moderna y de los marcos analíticos y teológicos más recientes de su tiempo, creo que igualmente hubiese incorporado la contribución del feminismo crítico si éste hubiera estado disponible en ese entonces. Pedirle a Medellín un riguroso análisis del grave sexismo cultural latinoamericano, 0 un análisis comprehensivo del neocapitalismo patriarcal, o una denuncia del pernicioso androcentrismo teológico constituye un anacronismo histórico y epistemológico. La actual racionalidad crítica feminista adquirió un perfil consistente sólo en décadas posteriores 
a Medellin. Este tipo de racionalidad ocupa hoy un lugar prominente en cualquier forma de abordar las dinámicas culturales, sociales y teológicas que buscan fundar modos nuevos de vida y de pensamiento; esto es, nuevos modelos de convivencia que sostienen la integridad de las personas, las razas, las etnias y los sistemas ecobióticos. Medellín es consistente con los desarrollos intelectuales de su tiempo, pero igualmente lo son la Iglesia y la teología en el presente. Consecuentemente, no podemos adjudicar a Medellín ni negligencia ni mala voluntad respecto de los desarrollos de la teologia feminisla crítica, aunque no podemos decir to mismo con respecto a la Iglesia y la actividad teológica realizada por teólogos y teólogas ya en el amanecer del tercer milenio. Nos hace falta hoy la sensibilidad espiritual, la creatividad intelectual, la intuición solidaria, y la visión integralmente liberadora de Medellín.

Paso ahora a contestar a la segunda pregunta: las exigencias de Medellín para la Iglesia y teología aciuales.

La naturaleza profética de Medellín proviene de su anuncio y vivencia de la visión del evangelio en su radicalidad transformadora dentro de realidades marcadas por el conflicto, la injusticia y la violencia institucionalizada ( $\mathrm{Paz} 16$ ). Mediante su clara toma de postura en favor de los grupos excluidos, Medellín alimenta la esperanza de estos grupos, defiende sus intereses contra los poderes dominantes, denuncia las raíces de la opresión, el pecado y la violencia, y participa activamente en la realización histórica del propósito salvífico de Dios. EI profetismo radical de Medellín sigue exigiendo de la Iglesia y de la teología una actitud de mayor honradez y valentía para enfrentar las situaciones de pecado y de miseria, que continúan golpeando a nuestros pueblos. Entre las muchas exigencias que Medellín sigue planteando, quiero subrayar sólo cinco.

1. Decir la verdad de la realidad. En la siluación presente, la Iglesia y la teología han de enfrentar con mayor criticidad y valentía los procesos económi$\cos$ y socio-culturales producidos por la globalización neoliberal y neocapitalista, que crecientemente van disminuyendo la calidad de vida de nuestros pueblos. Para ello, hemos de potenciar las fuerzas globalizadoras enraizadas en pueblos, culturas y movimientos socio-eclesiales que luchan por una civilización altemativa en favor de una mayor humanización y por la eliminación de la violencia estructural. Basadas en la visión cristiana de la justicia, la dignidad humana y el bien común, la Iglesia y la leología tienen necesidad de incorporar las teorías críticas de análisis sistérnico, las teorías críticas feminislas y los recientes estudios interculturales e interraciales que profundizan la identidad liberadora del cristianismo.

2. Enfrentar el pecado estructural del patriarcado y del sexismo. Para Medellín, el pecado estructural es la negación sistemática de la salvación (Justicia 3, Paz 1). Esta noción central está referida a la organización del todo social en estrucluras que crean y reproducen relaciones injustas en la vida pública y 
privada de la gente. Pero, además, con esta noción, Medellín quiere exponer la responsabilidad moral y religiosa de personas y grupos sociales ante las estructuras, instituciones e ideologías creadas por la acción humana que violan la dignidad de las personas y prohiben la integridad de la creación. En este sentido, la injusticia estructural, generada por la organización patriarcal de la Iglesia y la sociedad, debe ser enfrentada por la actual Iglesia y teología, debido a que el orden patriarcal constituye una base permanente de pecado estructural. Ya es tiempo de que la teología latinoamericana de la liberación nombre y enfrente el pecado del sexismo.

3. Violencia hacia las mujeres y la enseñanza social de la jerarquia eclesí́stica. Medellín entiende que "el sentido de servicio y realismo exige de la jerarquía de hoy mayor sensibilidad y objetividad sociales. Para ello, hace falta el contacto directo con los distintos grupos... para elaborar doctrina social aplicándola a nuestros problemas" (Justicia 18). El propósito de la enseñanza social de la jerarquía eclesiástica es "instaurar la justicia en Jas relaciones humanas" (Justicia 22). A esla luz, Medellín continúa desafiando la capacidad de la lglesia y de la leología para acercarse con mayor sensibilidad al grave problema de violencia social, familiar y doméstica, que afecta a la inmensa mayoría de mujeres en América Latina. Aunada a la violencia social experimentada continuamente por las mujeres indígenas y negras, la violencia doméstica y sexual atraviesa la existencia colidiana de estas y otras mujeres. Medellín exige de los teólogos, obispos y sacerdotes un contaclo directo con las víctimas de esta violencia y un dílogo directo con los grupos de mujeres y los movimientos feministas que ofrecen mejores respuestas al problema de la injusticia en las relaciones humanas.

4. Las implicaciones feministas de la opción por los pobres. Para la razón teórica modema, la opción por los pobres es un escándalo y es locura para la razón neoliberal postmodema. Pero para una mujer mestiza como yo, hija de familia campesina pobre que continúa debatiéndose entre la angustia y la incertidumbre (Pobreza 3), la opción por los pobres y oprimidos es fuente de fuerza y sabiduría. Como cristiana y como teóloga católica, Medellín me sigue exigiendo trabajar y abogar por la suerte de mi pueblo. Como mujer, como cristiana y como teóloga, Medellín inspira mi compromiso por vivir mi vocación teológica como activa contribución en el establecimiento de nuevas culturas, nuevas formas de relacionarse humanamente, y una nueva Iglesia libre de toda forma de exclusión y violencia. En la realidad presente, sin embargo, Medellín exige de la Iglesia, de teólogos y teólogas, una opeión consciente y deliberada por promover una mayor justicia y humanización de las mujeres, que continuamos viviendo bajo los poderes patriarcales, y un compromiso deliberado por promover la incorporación de las mujeres pobres en la empresa teológica liberadora. 
5. Compromiso con nuevas estructuras de Iglesia. Teniendo en cuenta la naturaleza de la Iglesia, Medellín implantó ya la semilla para emprender la revisión seria de las estructuras eclesiales "para satisfacer las exigencias de situaciones históricas concretas", pero en observancia de la comunión y la catolicidad (Pastoral de Conjunto 5). La visión que tiene Medellín de la identidad y la misión de la Iglesia incluye la búsqueda de nuevos modelos, libres de clericalismo y dominación patriarcal. Para Medellín, los principios que han de articular el ser de la Iglesia son la solidaridad, la colegialidad y la comunión (Pastoral de Conjunto 7, 9). Esta visión de Iglesia, porque está apoyada en la intrínseca dignidad bautismal y antropológica de cada creyente, admite la revisión de las estructuras eclesiales con el fin de eliminar la exclusión de las mujeres. Un nuevo modelo de Iglesia, que responde a los desafíos de las situaciones históricas en el tercer milenio, debe eliminar tal exclusión jurídica, sacramental y teológica. Vislumbramos aquí una Iglesia que busca concertar las fuerzas planetarias para establecer la justicia universal en un mundo donde toda la gente quepa.

\section{Medellín y el pueblo latino en Estados Unidos}

\section{Roberto S. Goizueta, Loyola University, Chicago.}

Como lalinoamericanos que vivimos en el primer mundo, y como una comunidad "invisible" dentro de la cultura dominante estadounidense, los que pertenecemos al pueblo latino en Estados Unidos recurrimos a la conferencia de Medellín como un momento histórico que reivindica nuestra propia historia, dignidad, valor e identidad latinoamericanas. Ese gran encuentro episcopal representa para los católicos latinos estadounidenses el reconocimiento y la afirmación de nuestra historia de sufrimiento frente a la historia de la conquista y la "evangelización" europea, por un lado, y, por el olro, frente a la cultura dominante euro-americana que, en Estados Unidos, está marcada por el liberalismo individualista, racionalista y consumista.

A final del segundo milenio, es imposible seguir pensando sobre la Iglesia como una comunidad e institución europea con misiones o "salélites" en otras partes del mundo; tres décadas después de Medellín, la realidad de nuestra Iglesia "policéntrica" es inocultable. Si hoy la Iglesia tiene un centro pastoral teológico, éste se encontrará no en las catedrales de París o Toledo, sino en los barrios pobres de São Paulo, Lima y Los Angeles. En Medellín, los obispos cumplieron el mandato del Concilio Vaticano II, que exigía una contextualización de la misión pastoral de la Iglesia, de tal manera que la pastoral parta de un análisis de "los 
signos de nuestros tiempos" y, por lo tanto, de un compromiso práctico con las luchas, anhelos, inquietudes y sufrimientos del pueblo que constituye la Iglesia. Como porlavoz del pueblo cristiano latinoamericano, Medellín representa la reivindicación de ese pueblo como parte de la Iglesia universal.

Cuando elaboran las implicaciones teológicas de la opción preferencial por los pobres (aun sin usar el conceplo explícitamente), los obispos en Medellín afirman la importancia de la marginación como locus theologicus; es ahí donde -de forma preferencial y privilegiada- se encuentra el Dios de Jesucristo, el Dios encamado en un carpintero, un galileo, rechazado por las élites de Jerusalén. Los obispos insisten en que "el particular mandato del Señor de 'evangelizar a los pobres' debe llevamos a una distribución de los esfuerzos y del personal apostólico que dé preferencia efectiva a los sectores más pobres y necesitados y a los segregados por cualquier causa, alentando y acelerando las iniciativas y estudios que con ese fin ya se hacen" (Medellín, 14, 9).

Si la doctrina social de la Iglesia nos obliga a responder caritativamente a las necesidades de los pobres del mundo, los documentos de Medellín nos hacen recordar que esa responsabilidad es tanto una condición como una consecuencia de nuestra fe cristiana: Jesucristo se ha identificado con los pobres y, por lo tanto, la Iglesia se ha de solidarizar con los pobres para descubrir allí su propia identidad y misión. "Cristo nuestro Salvador", afirman los obispos, "no sólo amó a los pobres, sino que 'siendo rico se hizo pobre', vivió en la pobreza, centró su misión en el anuncio a los pobres de su liberación y fundó su Iglesia como signo de esa pobreza entre los hombres" (Medellín, 14, 7). Paradójicamente, sólo por medio de una solidaridad preferencial con los pobres podrá la Iglesia llevar a cabo su misión universal y reconciliadora. El bien común no se podrá lograr hasta que se logre el bien particular de esos grupos que, hasta ahora, han sido segregados, excluídos y viclimizados.

Si Medellín propuso un nuevo punto de partida histórico-teológico y una nueva dirección pasloral para la Iglesja (por ejemplo, la opción preferencial por los pobres), la experiencia del pueblo latino estadounidense —un pueblo cuya cultura sigue siendo menospreciada y rechazada - nos ha ayudado a entender las dimensiones expresamente culturales y raciales de ese punto de partida. Si los obispos latinoamericanos desarrollan una metodología teológica-pastoral que parte de y conlleva a la solidaridad con los pobres, la marginalización cultural y racial que marca la historia de los latinos en Norte América nos hace recordar que la lucha por la justicia y la liberación que constituye el cimiento de la vida cristiana tiene muchos y diversos aspectos, ya que las causas de la "segregación" también son muchas y diversas.

Comprometidos con la lucha histórica de nuestro pueblo, los teólogos latinos estadounidenses hemos utilizado los aportes metodológicos de los obispos en Medellín y de los teólogos latinoamericanos para elablorar una teología propia- 
mente latina-estadounidense, una reflexión teológica contextual que eche raíces en esa lucha y que dé testimonio de la presencia liberadora del Señor en nuestra historia y cultura, y especialmente en nuestra religiosidad popular. Esa es la manera principal de afirmar el valor de nuestra historia y la dignidad de nuestro pueblo ante Dios y ante la cultura mayoritaria occidental, individualista y racionalista. Por eso, la religiosidad popular — como un momento imprescindible en el proyecto histórico de la liberación- sigue siendo un tema clave en las reflexiones de los teólogos latinos en Estados Unidos.

Sin embargo, si bien hemos recalcado el significado teológico y liberador de la religiosidad popular latina, ahora nos encontramos en un segundo momento de nuestro movimiento teológico, cuando empezamos a apreciar más profundamente el carácter ambiguo de la religiosidad popular. Con respecto a la ambjgüedad teológica de la religiosidad popular los documentos de Medellín están muy claros $(6,1-15)$. Los obispos nos exigen estudiar críticamente la religiosidad popular para poder discernir en ella los valores propiamente evangélicos y liberadores. La responsabilidad no sólo de afirmar el valor teológico de la religiosidad popular, sino de distinguir entre los valores y los desvalores es una tarea que, en Estados Unidos, los teólogos latinos ahora empezamos a desempeñar, ya que la primera urgencia ha sido la de recalcar el valor de nuestra religiosidad popular frente a una Iglesia y sociedad norleamericanas que rechazan cualquier forma de religiosidad que no parta de presupuestos epistemológicos individualistas o racionalistas.

Este proceso crítico requiere que, a la luz de Medellín y otros documentos eclesiales, los teólogos latinos norteamericanos desarrollemos una crítica más aguda y sistemática del sistema neoliberal vigente. $\mathrm{O}$ sea, debemos estudiar los vínculos entre la religiosidad popular, la cultura latina y el clasismo económico. La religiosidad popular (tanto como la cultura en general) no es una realidad abstracta y estática, sino concreta y dinámica; se desarrolla dentro de estructuras socioeconómicas que influyen en su forma, en su significado teológico-pastoral y en sus consecuencias políticas. La opresión racial o cultural siempre tiene mediaciones economómicas o clasistas. Uno de los desafíos más importantes para los próximos años será precisamente el de articular una critica sistemática y efectiva del sistema neoliberal que, aun en forma más compleja e ideologizada (desde la caída de las sociedades socialistas marxistas), sigue contribuyendo al empobrecimiento de los sectores populares mientras que enriquece a las élites locales y transnacionales, ya sea en San Salvador o Nueva York. Este hecho no debe desalentamos. Más que nunca, urge entablar un discurso interamericano sobre el neoliberalismo y sus efectos sociales en nuestras poblaciones. Con mayor urgencia que nunca necesitamos una crítica teológica del sistema económico global que, a falta de altemativas, se nos presenta hoy día como sistema absoluto e inviolable, como el "fin de la historia". 
En el pueblo latino estadounidense el sector que más sufre bajo el impacto y las consecuencias deshumanizantes de ese sistema es nuestra juventud, que también es el sector más numeroso del pueblo latino en Estados Unidos. Es una gran ironía que la sociedad estadounidense, que glorifica la "juvenlud" en su ideología y sus medios masivos de comunicación, desprecie tanto a sus propios jóvenes, especialmente a los jóvenes latinos y afroamericanos. Ese desprecio se manifesta en la pobreza de nuestras inadecuadas escuelas públicas y el abandono que experimentan millones de niños y jóvenes que viven en las calles de nuestras ciudades. El problema social que representan las pandillas o gangs, en las ciudades de Estados Unidos, especialmente en los barrios latinos o afroamericanos, es síntoma del desprecio de la juventud que subyace en la cultura dominante. La destrucción de nuestros jóvenes latinos se efectúa por medio de estructuras socioeconómicas que promueven el desarrollo de las élites y sus necesidades a la vez que incapacitan a los sectores populares. Frente a este escándalo e injusticia, la orientación pastoral de Medellín nos exige "desarrollar, en todos los niveles, en los sectores urbano y rural, dentro de la pastoral de conjunto, una auténtica pastoral de la juventud. Esta pastoral ha de tender a la educación de la fe de los jóvenes a partir de su vida, de modo que les permita su plena participación en la comunidad eclesial, asumiendo consciente y cristianamente su compromiso temporal" $(5,14)$. Al final del segundo milenio esa exigencia es más urgente que nunca.

La conferencia de Medellín sigue iluminando los pasos de la Iglesia en las Américas. Los rasgos del pueblo cristiano en América estarán para siempre marcados por las palabras y el espírilu profético de ese encuentro y los documentos promulgados en 1968. En las reflexiones precedentes he intentado presentar sólo algunos (hay muchos más) de los aportes y las paulas significativas de ese encuentro para el pueblo latino en Estados Unidos y, en particular, para la teología latina norteamericana. Como todos los cristianos en este hemisferio, estamos en profunda deuda con el espíritu de Medellín, el cual sigue animándonos mientras acompañanos al Salvador que "siendo rico se hizo pobre". 